\title{
Evaluation of the content and bioaccessibility of magnesium, manganese, zinc and copper from buckwheat groats produced in various conditions
}

\author{
Joanna Klepacka ${ }^{1}$, Agnieszka Najda $^{2}$, Kamila Klimek ${ }^{3}$, Elżbieta Tońska ${ }^{1}$ and Joanna Michalak ${ }^{1}$ \\ ${ }^{1}$ Department of Commodity Science and Food Analysis, The Faculty of Food Sciences, University of Warmia and \\ Mazury, Olsztyn, Poland, \\ ${ }^{2}$ Department of Vegetable Crops and Medicinal Plants, University of Life Sciences, Lublin, Poland and \\ ${ }^{3}$ Department of Applied Mathematics and Informatics, University of Life Sciences, Lublin, Poland
}

\section{Abstract}

In recent years special attention has been paid to gluten-free foods, and among them buckwheat grains are becoming more popular. They are a rich source of many nutrients, including mineral compounds, and are eaten in many forms, eg. as a "kasha" which is obtained from roasted and dehulled grains. Food processing causes various changes in chemical composition of raw materials and their rate depends on the treatment parameters, therefore the aim of the study was to determine how the content and bioavailability of selected minerals is influenced by conduction the buckwheat groats production under different conditions.

The experimental materials were buckwheat grains subjected in industrial conditions to a short hydrothermal treatment $\left(\mathrm{ca} .100^{\circ} \mathrm{C} /\right.$ $15 \mathrm{~min}$ ) conducted in cereal dryer (unroasted groats were obtained), and also roasted in pressure boilers $\left(140^{\circ} \mathrm{C} / 90 \mathrm{~min}, 0.4 \mathrm{MPa}\right)$ to receive roasted grains. The content of selected minerals $(\mathrm{Mg}, \mathrm{Mn}, \mathrm{Zn}, \mathrm{Cu})$ was determined by flame atomic absorption spectrometry and their bioavailability was determined by enzymatic hydrolysis in vitro in a system, which simulated the conditions in the human gastrointestinal tract.

It was shown that different conditions of applied hydrothermal treatment had a lesser influence on the total content of analyzed minerals (determined before the digestion process), but they significantly influenced their bioaccessibility. Short treatment carried out at a lower temperature had a beneficial effect on the availability of all determined elements, increasing it to the greatest extent for $\mathrm{Mg}$ and $\mathrm{Mn}$.

This process caused an increase in the content of $\mathrm{Mg}$ released after digestion from $859.4 \mu \mathrm{g} / \mathrm{g}$ (unheated grains) to $1233.8 \mu \mathrm{g} / \mathrm{g}$ (unroasted groats), and the Mn level increased respectively from 2.61 to $5.19 \mu \mathrm{g} / \mathrm{g}$. The roasting process statistically significantly $(\mathrm{p}<0.001)$ reduced the level of these elements (to $836.1 \mu \mathrm{g} / \mathrm{g}$ for $\mathrm{Mg}$ and $1.99 \mu \mathrm{g} / \mathrm{g}$ for $\mathrm{Mn}$ ). The high parameters of seed treatment used during roasting also caused a decrease in the availability of other elements and their effect was most noticeable for Zn, whose level decreased from $31.99 \mu \mathrm{g} / \mathrm{g}$ (unheated grains) to $9.97 \mu \mathrm{g} / \mathrm{g}$ (roasted groats).

Observed dependencies allow to state, that due to the bioaccessibility of minerals, it is more beneficial to treat buckwheat grains with a lower temperature in a short time, and therefore consumers who pay attention to the nutritional value of the food, should choose unroasted buckwheat groats.

\section{Conflict of Interest}

There is no conflict of interest 